\title{
The Safety Profile of General and Local Anaesthetic Agents: Data Collected during 20 Years of Spontaneous Reporting Activities in the Campania Region (Southern Italy)
}

\author{
Francesca Gargano ${ }^{1, \dagger}$, Cristina Scavone ${ }^{2,3, *,+}+\mathbb{C}$, Gabriella di Mauro ${ }^{2,3}$, Alberto Della Corte ${ }^{3}$, Alice Zoccoli ${ }^{4}$, \\ Francesco Rossi ${ }^{2,3,4}$, Giovanni Francesco Nicoletti ${ }^{5, \ddagger}$ and Annalisa Capuano ${ }^{2,3, \ddagger}$ \\ 1 UOC Anestesia e Rianimazione, Policlinico Universitario Campus Bio-Medico, 00128 Rome, Italy; \\ f.gargano@unicampus.it \\ 2 Campania Regional Centre for Pharmacovigilance and Pharmacoepidemiology, 80138 Naples, Italy; \\ gabriella.dimauro@unicampania.it (G.d.M.); francesco.rossi@unicampania.it (F.R.); \\ annalisa.capuano@unicampania.it (A.C.) \\ 3 Department of Experimental Medicine, University of Campania “Luigi Vanvitelli”, 80138 Naples, Italy; \\ albertodellacorte@live.it \\ 4 Clinical Innovation Office, Università Campus Bio-Medico, 00128 Rome, Italy; a.zoccoli@unicampus.it \\ 5 Multidisciplinary Department of Medical Surgical and Dental Sciences, Plastic Surgery Unit, \\ University of Campania “Luigi Vanvitelli", 80138 Napoli, Italy; giovannifrancesco.nicoletti@unicampania.it \\ * Correspondence: cristina.scavone@unicampania.it \\ + Authors have contributed equally to this work and share first authorship. \\ $\ddagger$ Co-lead authors.
}

Citation: Gargano, F.; Scavone, C.; di Mauro, G.; Corte, A.D.; Zoccoli, A.; Rossi, F; Nicoletti, G.F.; Capuano, A. The Safety Profile of General and Local Anaesthetic Agents: Data Collected during 20 Years of Spontaneous Reporting Activities in the Campania Region (Southern Italy). Pharmaceuticals 2021, 14, 1261. https://doi.org/10.3390/ph14121261

Academic Editors: Tuomas Lilius and Teijo Saari

Received: 19 October 2021

Accepted: 1 December 2021

Published: 3 December 2021

Publisher's Note: MDPI stays neutral with regard to jurisdictional claims in published maps and institutional affiliations.

Copyright: () 2021 by the authors. Licensee MDPI, Basel, Switzerland. This article is an open access article distributed under the terms and conditions of the Creative Commons Attribution (CC BY) license (https:// creativecommons.org/licenses/by/ $4.0 /)$.
Abstract: Background: General and local anaesthetics are widely used during surgery. These drugs have peculiar safety profiles, being commonly associated with mild and reversible local adverse drug reactions (ADRs), but also with more severe and systemic ADRs, including respiratory and cardiovascular depression and anaphylaxis. Methods and Objectives: We carried out a descriptive analysis of Individual Case Safety Reports (ICSRs) sent to the Campania Regional Centre of Pharmacovigilance (Southern Italy) from 2001 to 2021 that reported general or local anaesthetics as suspected drugs, with the aim of describing their overall characteristics, focussing on the ADRs' seriousness and distribution by System Organ Class (SOC) and Preferred Term (PT). Results: A total of 110 ICSRs documenting general or local anaesthetics were sent to the Italian pharmacovigilance database during 20 years of spontaneous reporting activities in the Campania region. ADRs mainly occurred in patients with a median age of 48 years and in a slightly higher percentage of men. ADRs were more commonly classified as not serious and had a favourable outcome. In terms of ADRs' distribution by SOC and PT, both general and local anaesthetics were associated with general and cutaneous disorders, with common ADRs that included lack of efficacy, rash, and erythema. In addition, general anaesthetics were associated with the occurrence of respiratory ADRs, while local anaesthetics were associated with the occurrence of nervous ADRs. Conclusion: Even though a limited number of ICSRs documenting anaesthetics-induced ADRs were retrieved from the Italian spontaneous reporting database in the Campania region, we believe that the continuous monitoring of these drugs is highly recommended, especially among the frail population.

Keywords: general anaesthetics; local anaesthetics; safety; spontaneous reporting system

\section{Introduction}

Anaesthesia can be successfully achieved with a wide range of drugs that include general and local anaesthetics, but also analgesics, sedatives, and neuromuscular blocking drugs. General anaesthetics represent one the most important drugs for surgical procedures. They induce a state of controlled and reversible loss of consciousness that is the result of sedation, amnesia, and muscle paralysis [1]. Drugs used in general anaesthesia belong to 
different therapeutic classes with diverse mechanisms of action (mainly an enhancement of inhibitory neurotransmissions or a reduction of excitatory neurotransmissions), and are generally administered via different routes. Among intravenous anaesthetics, propofol is a phenol agent that is used for the induction and maintenance of anaesthesia; etomidate is an ultrashort-acting, non-barbiturate hypnotic that is usually used only for induction; while ketamine is a dissociative anaesthetic that produces intense analgesia. Inhalational anaesthetics (such as nitrous oxide, which is a gas, and sevoflurane, desflurane and isoflurane, which are liquids) are rapidly absorbed at the level of pulmonary alveoli. They are mainly used for the maintenance of anaesthesia. Another drug class that has been widely used for the induction of anaesthesia is represented by barbiturates (mainly thiopental) [2]. However, given their peculiar safety profile (risk of addiction, overdose, and death), the use of barbiturates was gradually replaced by safer anaesthetic agents for intravenous administration [3]. Intravenous sedatives, mainly benzodiazepines, are commonly used as premedication agents. Among this class, midazolam is the most widely used, both before the anaesthesia induction for its sedative, anxiolytic, and amnestic properties, and for co-induction in order to speed up the onset of hypnosis and to reduce the doses required of other anaesthetics [4,5]. Synthetic opioids such as sufentanil, remifentanil, and fentanyl are commonly used for their potent analgesic effect in surgery units where ventilatory support is readily available. Lastly, neuromuscular blocking drugs (such as succinylcholine, cisatracurium, and rocuronium) act on the postsynaptic membrane of nicotinic cholinergic receptors [6-8]. On the other hand, the effects of local anaesthetics derive from the blocking of nerve impulse transmission in the peripheral and central nervous system (CNS), even though they do not cause CNS depression or an altered mental status. These drugs are commonly used to induce reversible anaesthetic effects during local surgical procedures (epidural and spinal blocks). Among this class, lidocaine, mepivacaine, ropivacaine, bupivacaine, levobupivacaine, and procaine are the local anaesthetics most commonly used $[9,10]$. As reported in the latest OsMed Report of the Italian Medicines Agency (AIFA-https: //www.aifa.gov.it/documents/20142/1542390/Rapporto-OsMed-2020.pdf, accessed on 26 November 2021), an increase in the use of injecting drugs was recorded in Italy in 2020, including neuromuscular blocking drugs, hypnotics, sedatives, and general anaesthetics.

Regarding to the safety profile of anaesthetics, the occurrence of adverse drug reactions (ADRs) is common during general anaesthesia. Indeed, general anaesthetic can commonly induce confusion or memory loss, dizziness, urinary retention, nausea, vomiting, and chills [11]. In addition, depending on the type of general anaesthetic that is used, further ADRs could commonly occur, such as a profound respiratory depression, hypotension, and bradycardia until cardiac arrest due to the induction dose of propofol; nausea or vomiting after etomidate; laryngospasm and hallucinations after ketamine; or meiosis, respiratory depression, bradycardia, constipation, and urinary retention after opioids [11]. Inhalational anaesthetics can induce cardiovascular, renal, hepatic, and gastrointestinal toxicities [12]. On the other hand, benzodiazepines can be associated with other types of ADRs, including thrombophlebitis, thrombosis, anterograde amnesia, drowsiness, ataxia, falls, and confusion. Some of these ADRs are more common in the elderly [13]. Lastly, depending on the type of neuromuscular blocking drug, cardiac and cutaneous ADRs may occur $[14,15]$. Regarding the safety profile of local anaesthetic, the most common ADRs are represented by those occurring in the application site, which includes pain, erythema, and oedema [16]. When the plasmatic level of the anaesthetic rises to concentrations above those recommended, so-called local anaesthetic systemic toxicity could occur. This is the most severe, but rare, ADR associated with local anaesthetics, with symptoms that include paraesthesia, dysarthria, diplopia, ear disturbances, seizures, hypertension, and tachycardia. Severe cases progress to CNS and respiratory depression, with cardiovascular effects that include myocardial depression, prolonged conduction interval, bradycardia, and heart failure [17]. An overview of ADRs associated with drugs used during general and local anaesthesia is reported in Table 1. 
Table 1. Adverse drug reactions associated with drugs used in general and local anaesthesia.

\begin{tabular}{|c|c|}
\hline Drug(s) & Adverse Drug Reactions \\
\hline Propofol & $\begin{array}{ll}\text { - } & \text { Depression } \\
\text { - } & \text { Hypotension } \\
\text { - } & \text { Bradycardia and cardiac arrest } \\
\text { - } & \text { Increase in triglycerides }\end{array}$ \\
\hline Etomidate & - $\quad$ PONV \\
\hline Ketamine & $\begin{array}{ll}\text { - } & \text { Hypertension } \\
\text { - } & \text { Hypersalivation } \\
\end{array}$ \\
\hline $\begin{array}{l}\text { Inhalational anaesthetics } \\
\text { (nitrous oxide, } \\
\text { sevoflurane, desflurane, } \\
\text { isofluran) }\end{array}$ & $\begin{array}{l}\text { - } \quad \text { Nephrotoxicity and hepatotoxicity } \\
\text { - } \quad \text { Arrhythmias } \\
\text { - } \quad \text { PONV } \\
\text { - } \quad \text { Malignant hyperthermia and post-anaesthesia agitation }\end{array}$ \\
\hline Thiopental & $\begin{array}{ll}\text { - } & \text { Increase in blood pressure } \\
\text { - } & \text { Nausea } \\
\text { - } & \text { Risk of addiction, overdose, and death }\end{array}$ \\
\hline Benzodiazepines & 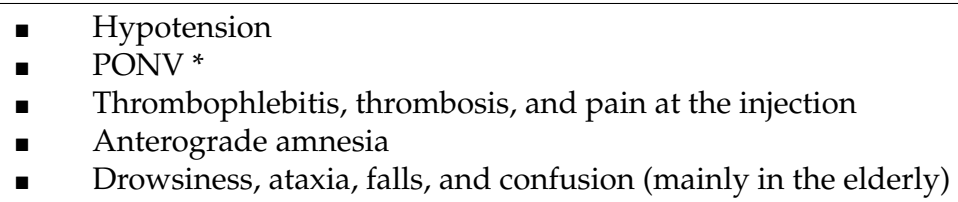 \\
\hline $\begin{array}{l}\text { Synthetic opioids } \\
\text { (sufentanil, remifentanil, } \\
\text { fentanyl) }\end{array}$ & $\begin{array}{ll}\text { - } & \text { Meiosis } \\
\text { - } & \text { Respiratory depression } \\
\text { - } & \text { Bradycardia } \\
\text { - } & \text { PONV } \\
\text { - } & \text { Urinary retention }\end{array}$ \\
\hline $\begin{array}{l}\text { Neuromuscular blocking } \\
\text { drugs (succinylcholine, } \\
\text { cisatracurium, } \\
\text { rocuronium) }\end{array}$ & $\begin{array}{l}\text { - Cardiovascular symptoms } \\
\text { - } \quad \text { Cutaneous erythema }\end{array}$ \\
\hline $\begin{array}{c}\text { Local anaesthetics } \\
\text { (lidocaine, mepivacaine, } \\
\text { ropivacaine, } \\
\text { bupivacaine, } \\
\text { levobupivacaine, } \\
\text { procaine) }\end{array}$ & $\begin{array}{l}\text { - Application site reactions (pain, erythema, and oedema) } \\
\text { - } \quad \text { Local anaesthetic systemic toxicity (rare) }\end{array}$ \\
\hline
\end{tabular}

Considering that general and local anaesthetics are widely used during surgical procedures, and given their peculiar safety profiles, we carried out a pharmacovigilance study using data from the Italian spontaneous reporting system to describe regional Individual Case Safety Reports (ICSRs) documenting the aforementioned suspected drugs, with the aim of describing the overall characteristics of these ICSRs, focussing on their seriousness and distribution by System Organ Class (SOC) and Preferred Term (PT).

\section{Results}

From 1 January 2001 until 7 September 2021, the Campania Regional Centre of Pharmacovigilance received 110 ICSRs, covering 176 ADRs, that reported general and local anaesthetic medicines as suspected (50 ICSRs and 60 ICSRs, 86ADRs and 90 ADRs, respectively). Overall, anaesthetics-induced ADRs occurred in patients with a median age of 48.5 years and in a slightly higher percentage of male patients $(51 \%)$ than female patients $(46.3 \%)$. The majority of ICSRs (58.2\%) reported ADRs that were classified as not serious; however, the remaining ICSRs mainly reported serious ADRs that were clinically relevant or life-threatening (15.5\% and $12.7 \%$, respectively) (Table 2$)$. Regarding ICSRs which reported life-threatening ADRs, 14 cases were retrieved from the National Pharma- 
covigilance Network (Rete Nazionale di Farmacovigilanza-RNF) in the Campania region. These mainly reported general anaesthetics as suspected (in 11/14; propofol was reported as suspected in 8 ICSRs). The age of the patients ranged from 2 to 67 years; half of these ICSRs referred to female patients and half to males. In most of cases, life-threatening ADRs were represented by hypersensitivity reactions that occurred shortly after the administration of the anaesthetic, including many cases of bronchospasm, rash, and cardiovascular symptoms (hypotension, bradycardia, and tachycardia) (Table 3). For all ICSRs (serious and not serious), the outcome was favourable in $71 \%$ of cases and unfavourable in $5.4 \%$ of cases (Table 2). Lastly, almost $97 \%$ of ICSRs $(n=107)$ were sent by healthcare professionals, while the remaining $3 \%$ were sent by patients (data not shown).

Table 2. Main characteristics of individual case safety reports which had general and local anaesthetic medicines as suspected drugs sent through the Campania region spontaneous reporting system, from January 2001 to September 2021.

\begin{tabular}{|c|c|c|c|c|}
\hline Variable & Level & $\begin{array}{l}\text { All ICSRs } \\
(n=110)\end{array}$ & $\begin{array}{l}\text { ICSRs Reporting } \\
\text { General Anaesthetic } \\
\text { as Suspected Drugs } \\
(n=50) *\end{array}$ & $\begin{array}{l}\text { ICSRs Reporting local } \\
\text { Anaesthetic as } \\
\text { Suspected Drugs } \\
(n=60) * *\end{array}$ \\
\hline Age, years & Median (IQR) & $48.5(30.75-64.25)$ & $41(16-59)$ & $55(39-69)$ \\
\hline \multirow[t]{3}{*}{ Sex } & Female & $51(46.3)$ & $22(44)$ & $29(48)$ \\
\hline & Male & $56(51)$ & $26(52)$ & $30(50)$ \\
\hline & Missing & $3(2.7)$ & $2(4)$ & $1(2)$ \\
\hline \multirow[t]{5}{*}{ Seriousness } & Hospitalisation or its prolongation & $9(8.2)$ & $6(12)$ & $3(5)$ \\
\hline & Clinically relevant & $17(15.5)$ & $6(12)$ & $11(18)$ \\
\hline & Life-threatening & $14(12.7)$ & $11(22)$ & $3(5)$ \\
\hline & Not serious & $64(58.2)$ & $25(50)$ & $39(65)$ \\
\hline & Not defined & $6(5.4)$ & $2(4)$ & $4(7)$ \\
\hline \multirow[t]{3}{*}{ Outcome } & $\begin{array}{c}\text { Unfavourable (resolved with sequelae } \\
\text { or unchanged) }\end{array}$ & $6(5.4)$ & $3(6)$ & $3(5)$ \\
\hline & $\begin{array}{c}\text { Favourable (completely resolved or } \\
\text { improvement) }\end{array}$ & $78(71)$ & $37(74)$ & $41(68)$ \\
\hline & Not available & $26(23.6)$ & $10(20)$ & $16(27)$ \\
\hline
\end{tabular}

${ }^{*}$ General anaesthetics reported as suspected: cisatracurium $(n=1)$, fentanyl $(n=12)$, mivacurium $(n=2)$, propofol $(n=39)$, remifentanil $(n=1)$, rocuronium $(n=6)$, sevoflurane $(n=4)$, and sufentanil $(n=3) .{ }^{* *}$ Local anaesthetics reported as suspected: articaine $(n=1)$, bupivacaine $(n=27)$, levobupivacaine $(n=6)$, lidocaine $(n=3)$, lidocaine/prilocaine $(n=2)$, mepivacaine $(n=7)$, prilocaine $(n=2)$, and ropivacaine $(n=14)$. The total number of suspected drugs exceeds the total number of ICSRs by general and local anaesthetics, since in a single ICSR more than one suspected drug can be reported.

Table 3. Individual Case Safety Reports reporting general or local anaesthetic as suspected drugs and adverse drug reactions that were life-threating.

\begin{tabular}{|c|c|c|c|c|c|}
\hline Case $n$. & Age & Sex & Outcome & ADR (s) & Suspected Drug (s) \\
\hline 1 & 60 & $\mathrm{~F}$ & UU & Quincke's oedema, bronchospasm, rash & propofol, cisatracurium, sufentanil \\
\hline 2 & 63 & M & NA & Hypotension, bradycardia & sevoflurane \\
\hline 3 & 48 & $\mathrm{~F}$ & FCR & Bradyarrhythmia & sufentanil \\
\hline 4 & 3 & M & FCR & Cyanosis, Oxygen saturation abnormal & propofol \\
\hline 5 & 6 & $\mathrm{~F}$ & FCR & $\begin{array}{c}\text { Cyanosis, Laryngospasm, Loss of consciousness, } \\
\text { Tachycardia }\end{array}$ & propofol \\
\hline 6 & 4 & M & FCR & $\begin{array}{l}\text { Low oxygen saturation, tachycardia, } \\
\text { temporomandibular joint dysfunction }\end{array}$ & propofol \\
\hline 7 & 44 & $\mathrm{~F}$ & FI & Rash & propofol \\
\hline 8 & 3 & M & FCR & Bronchospasm, rash & propofol \\
\hline 9 & 7 & $\mathrm{~F}$ & FCR & Bronchospasm & propofol \\
\hline 10 & 2 & M & FCR & Bronchospasm, rash, absence of pulse & propofol \\
\hline 11 & 54 & $\mathrm{~F}$ & FCR & $\begin{array}{c}\text { Bronchospasm, diffuse erythema, oedema of the } \\
\text { glottis, excessive bronchial secretion }\end{array}$ & propofol, fentanyl, rocuronium \\
\hline 12 & 67 & M & URS & Hypotonia, flaccid paralysis & ropivacaine \\
\hline
\end{tabular}


Table 3. Cont.

\begin{tabular}{cccccc}
\hline Case $n$. & Age & Sex & Outcome & ADR (s) & Suspected Drug (s) \\
\hline 13 & 49 & M & FI & $\begin{array}{c}\text { Accelerated hypertension, coma, respiratory failure, } \\
\text { generalised convulsions, tachycardia }\end{array}$ & mepivacaine, levobupivacaine \\
\hline 14 & 26 & F & FCR & $\begin{array}{c}\text { Breathing difficulties, Sensation of crawling insects, } \\
\text { hypophonesis }\end{array}$ & bupivacaine \\
\hline
\end{tabular}

FCR: Favourable-completely resolved; FI: favourable-improvement; NA: not available; URS: unfavourable-resolved with sequelae; UU: unfavourable-unchanged.

By observing the ICSRs related to general and local anaesthetics, some differences can be highlighted. For instance, the percentage of not-serious ADRs is higher for local anaesthetic than for general ones ( $65 \%$ vs. $50 \%$, respectively), while the percentage of serious life-threatening ADRs is higher for general anaesthetic than for local ones ( $22 \% \mathrm{vs}$. $5 \%$, respectively) (Table 2 ).

Lastly, the distribution of ADRs by SOC and PT revealed that for general anaesthetic ADRs were more commonly related to the SOC "skin and subcutaneous tissue disorders" (22\%); followed by "respiratory, thoracic, and mediastinal disorders" (14\%); and "general disorders and administration site conditions" (13\%). Regarding the distribution by PT, we found that for cutaneous disorders the most reported ADRs were rash and erythema (twelve cases and four cases, respectively), bronchospasms for respiratory disorders (five cases), and lack of efficacy for general disorders (ten cases) (Table 4). SOCs that were most commonly reported for local anaesthetic were "general disorders and administration site conditions" (58\% of all local anaesthetic-induced ADRs), followed by "skin and subcutaneous tissue disorders" (11\%), and "nervous system disorders" (9\%). Among these SOCs, the PTs most commonly reported were a lack of efficacy and pain for general disorders (forty-two cases and seven cases, respectively), rash and angioedema for cutaneous ADRs (two cases each), and paralysis for CNS disorders (two cases) (Table 4).

Table 4. Distribution of adverse drug reactions related to general and local anaesthetic by System Organ Classes and Preferred Terms.

\begin{tabular}{|c|c|c|}
\hline System Organ Class & $\begin{array}{l}\text { General Anaesthetic } \\
\quad(n=86 ; 100 \%)\end{array}$ & $\begin{array}{l}\text { Local Anaesthetic } \\
\quad(n=90 ; 100 \%)\end{array}$ \\
\hline Cardiac disorders $n .(\%)$ & $6(7)$ & $3(3)$ \\
\hline Bradyarrhythmia & 1 & - \\
\hline Bradycardia & 1 & 2 \\
\hline Paroxysmal atrial fibrillation & 1 & - \\
\hline Tachycardia & 3 & 1 \\
\hline Gastrointestinal disorders & $9(10)$ & - \\
\hline Nausea & 5 & - \\
\hline Vomiting & 4 & - \\
\hline General disorders and administration site conditions & $11(13)$ & $52(58)$ \\
\hline Face oedema & - & 1 \\
\hline Lack of efficacy & 10 & 42 \\
\hline Neck oedema & - & 1 \\
\hline Pain & - & 7 \\
\hline Pyrexia & 1 & 1 \\
\hline Investigations & $8(9)$ & $1(1)$ \\
\hline Absence of pulse & 1 & - \\
\hline Hypophonesis & - & 1 \\
\hline Hypotension & 2 & - \\
\hline Increase in hepatic enzymes & 3 & - \\
\hline Low oxygen saturation & 2 & - \\
\hline Musculoskeletal and connective tissue disorders & $3(3)$ & - \\
\hline Dysfunction of the temporomandibular joint & 1 & - \\
\hline Muscle stiffness & 1 & - \\
\hline Rhabdomyolysis & 1 & - \\
\hline
\end{tabular}


Table 4. Cont.

\begin{tabular}{|c|c|c|}
\hline System Organ Class & $\begin{array}{l}\text { General Anaesthetic } \\
\qquad(n=86 ; 100 \%)\end{array}$ & $\begin{array}{l}\text { Local Anaesthetic } \\
\qquad(n=90 ; 100 \%)\end{array}$ \\
\hline Nervous system disorders & $4(5)$ & $8(9)$ \\
\hline Clonus & - & 1 \\
\hline Coma & - & 1 \\
\hline Dysesthesia & - & 1 \\
\hline Hypotonia & - & 1 \\
\hline Loss of consciousness & 1 & - \\
\hline Paralysis & - & 2 \\
\hline Psychomotor agitation & 1 & - \\
\hline Seizure & - & 1 \\
\hline Sensation of crawling insects & - & 1 \\
\hline Tremors & 2 & - \\
\hline Renal and urinary disorders & $3(3)$ & - \\
\hline Abnormal urine colour & 3 & - \\
\hline Respiratory, thoracic, and mediastinal disorders & $12(14)$ & $6(7)$ \\
\hline Bronchospasm & 5 & 1 \\
\hline Dyspnoea & 1 & - \\
\hline Excessive bronchial secretion & 1 & - \\
\hline Laryngospasm & 1 & - \\
\hline Oedema of the glottis & 1 & - \\
\hline Respiratory arrest & 1 & 1 \\
\hline Respiratory failure & - & 1 \\
\hline Shortness of breath & 1 & 1 \\
\hline Throat constriction & 1 & 2 \\
\hline Skin and subcutaneous tissue disorders & $19(22)$ & $10(11)$ \\
\hline Angioedema & - & 2 \\
\hline Desquamation & - & 1 \\
\hline Erythema & 4 & 1 \\
\hline Goose bumps & - & 1 \\
\hline Petechiae & - & 1 \\
\hline Pruritus & - & 1 \\
\hline Quincke's oedema & 1 & - \\
\hline Rash & 12 & 2 \\
\hline Redness & - & 1 \\
\hline Sweating & 2 & - \\
\hline Vascular disorders n. (\%) & $5(6)$ & $5(6)$ \\
\hline Cyanosis & 3 & 1 \\
\hline Hypertension & - & 1 \\
\hline Hypotension & 1 & 3 \\
\hline Venous thrombosis & 1 & - \\
\hline \multicolumn{3}{|c|}{ Other SOCs } \\
\hline Ear and labyrinth disorders & $2(2)$ & $1(1)$ \\
\hline Eye disorders & $1(1)$ & - \\
\hline Immune disorders & - & $1(1)$ \\
\hline Injury, poisoning, and procedural complications & $2(2)$ & - \\
\hline Investigations & - & 1 (1) \\
\hline Psychiatric disorders & 1 (1) & - \\
\hline Reproductive system and breast disorders & - & $1(1)$ \\
\hline Surgical and medical procedures & - & $1(1)$ \\
\hline
\end{tabular}

\section{Discussion}

During the first 20 years of spontaneous reporting activities in the Campania region (Southern Italy), 110 ICSRs that documented general and local anaesthetic medicines as suspected were collected. Reported ADRs occurred in patients with a median age of 48 years and in a slightly higher percentage of men $(51 \%)$ than women $(46.3 \%)$. To our knowledge, only a few drug utilisation studies evaluated the use of anaesthetics by age groups. As reported by Purdon and Turrentine, a high proportion of the patients who 
undergo anaesthetic procedures in the USA are aged 60 years or older [18,19]. Despite the increase of surgical procedures for the elderly, a retrospective study that examined the use of anaesthetic drugs in more than 30000 patients, showed a decreased utilisation of fentanyl, propofol, thiopental, isoflurane, and midazolam with increasing age [20]. Thus, the older age of patients who experienced anaesthetics-induced ADRs in our study could be related both to differences in how patients of different age groups react to anaesthetics and modifications in liver and kidney function in the elderly population. Indeed, the elderly seem to be more sensitive to anaesthetic agents and their potential complications, including ADRs [21]. Regarding the distribution of ICSRs by gender, we found a slightly higher percentage of male patients experiencing anaesthetic-induced ADRs, which seems to be in contrast with the literature data reporting a higher risk of ADRs from the suspected drugs for women due to sex-related factors in the pharmacokinetic and pharmacodynamic behaviour of drugs. Indeed, the risk for women of developing an ADR is 1.5- to 1.7-fold higher compared to men [22,23]. This was previously reported for other classes of druginduced ADRs in other studies [24-26]. However, as reported by Nicolson et al., many drug classes exhibit sex-based variation in pharmaceutical efficacy and toxicity, including anaesthetics [27].

Most of the ICSRs, especially those related to local anaesthetics, reported ADRs that were classified as not serious. In addition, the outcome was favourable in $71 \%$ of cases. This is in line with the literature data suggesting that local anaesthetics can be considered safe medications when they are used in proper doses and concentrations [28], even though serious ADRs, both local and systemic, could occur. Indeed, regarding the ICSRs documenting serious ADRs, we found that clinically relevant or life-threatening ADRs were the most common. In particular, life-threatening ADRs were mainly reported for general anaesthetics, especially propofol. In most cases, life-threatening ADRs were represented by hypersensitivity reactions. As reported by Gerald W Volcheck, hypersensitivity reactions, which could occur both during general and local anaesthesia, are associated with significant morbidity and mortality. The occurrence of such ADRs depend on many factors, including the large number of medications administered in the same time frame, such as neuromuscular blocking agents, antibiotics, and latex, which are the most common causes of anaesthesia-associated allergic reactions [29]. The incidence of anaphylaxis during anaesthesia was estimated to be between 1/1250 and 10000 [30], while the associated mortality rate varies across countries, ranging from $4.76 \%$ in Japan, $4 \%$ in the United States, $9 \%$ in the United Kingdom, and 0 to $1.4 \%$ in Western Australia [31-33]. Reasons underlying the high mortality rate associated with anaphylaxis include patient frailty (mainly depending on comorbid conditions), the cardiopulmonary depressive effects of anaesthetics, and the intravenous administration of massive doses of general anaesthetics [29].

Almost $97 \%$ of ICSRs were sent by healthcare professionals while the remaining 3\% were sent by patients. This is in line with findings from previous studies [34,35] and could be related to the new pharmacovigilance legislation which has further increased the involvement of healthcare professionals (HCPs) in pharmacovigilance activities [36,37]. On the other hand, the limited contribution of patients to the collection of ICSRs could be related to several factors, including a low education in terms of pharmacovigilance that still persists, not only among patients/citizens but also in the specific clinical field of our study. Indeed, patients admitted to surgery units might be less inclined to report ADRs compared to patients admitted to other clinical units because of the administered drugs and their related memory loss effects.

Regarding the distribution of ADRs by SOCs and PTs, we found that general anaesthetics were mainly associated with cutaneous and respiratory disorders and that the most commonly reported PTs were rash, erythema, and bronchospasms. In our opinion, these symptoms represent the main features of allergic reactions, which could occur abruptly with symptoms that include cardiovascular collapse, bronchospasm and cyanosis, sinus tachycardia and dysrhythmias, cutaneous and mucosal angioedema, urticaria and generalised erythema, vomiting, and abdominal cramps [38]. Among general disorders, the 
most commonly reported PT was the lack of efficacy. During general anaesthesia, this event is commonly defined as anaesthesia awareness, indicating the situation that occurs when a patient becomes aware of some or all events occurring during surgery. The risk for awareness is almost $0.1 \%$; young age, female sex, and cardiac or obstetric surgery carries a higher risk for this event $[39,40]$.

On the other hand, we found that local anaesthetics were mainly associated with general disorders (mainly lack of efficacy), cutaneous and nervous disorders (with common signs and symptoms that included rash, angioedema, and paralysis). In our opinion, the occurrence of cutaneous ADRs is not surprising considering that, as previously reported [16], local anaesthetics are mainly associated with ADRs occurring in the application site. In addition, in line with our results, another study carried out in France based on data from the spontaneous reporting system reported that the block failure-defined as insufficient or inadequate sensory anaesthesia-was the most frequent ADR reported with allergic manifestations (oedema, skin eruptions, anaphylactic reactions, and urticaria) and neurological symptoms (including paralysis) [41].

Regarding cases with a lack of efficacy related to both types of medications, we cannot exclude the possibility that they could represent the consequences of a clinical errors in the anaesthetic procedure/administration, rather than an ADR. Indeed, according to Orser et al., medication errors, deriving for instance from misidentification of ampoules, vials, and syringes, still represent a leading cause of ADRs among patients undergoing anaesthesia [42].

Apart from the well-known limitations of spontaneous reporting systems (spontaneous reports represent a voluntary communication from patients and physicians; the underreporting phenomenon; the lack of important clinical data in ICSRs (including gender, ADR seriousness/outcome, and anaesthetic dose) that-in our opinion-can be considered a consequence of the voluntariness of spontaneous reporting of suspected ADRs), which inevitably have affected our study, there are further limitations strictly related to our study that need to be stated. Firstly, we carried out a study using data from a single Italian region, which limits the generalisability of our results. We are aware that further studies based on data from larger pharmacovigilance databases, e.g., the EudraVigilance, are strongly needed in order to confirm the incidences of the anaesthetics-induced ADRs identified in our study. Secondly, many ICSRs did not report information on the outcome of ADRs; in our opinion, this was possibly related to the setting where we carried out the study, considering that at surgery units the patient's stay is usually limited in time. Thirdly, a reporting bias may have affected the degree of seriousness of the anaesthetics-induced ADRs; indeed, almost all of the ICSRs in our study were reported by healthcare professionals who seem to be more inclined to report serious ADRs.

On the other hand, we were able to provide a descriptive analysis of the spontaneous reporting system activities — related to anaesthetic drugs — that have been carried out in the Campania region since 2001. In addition, as recently reported by Raschi et al. [43], data from pharmacovigilance databases (such as the RNF that we used for our study) represent an unprecedented opportunity to provide a real-time overview of major drugsrelated toxicities. As a matter of fact, among anaesthetic-induced ADRs, we described those that were considered as life-threating, highlighting that many cases were related to hypersensitivity reactions, but we also found many cases related to anaesthesia block failure. Given their seriousness, in our opinion, the occurrence of these ADRs should be prevented as much as possible (for instance, through the consideration of the patient's history of allergies, and providing sufficiently deep anaesthesia or optimising the use of muscle relaxants) and strictly monitored.

\section{Materials and Methods}

\subsection{Data Sources}

The Italian spontaneous reporting system is coordinated by the Italian Medicines Agency (AIFA). The collection of ICSRs is made through the Italian spontaneous reporting 
database (Rete Nazionale di Farmacovigilanza-RNF) that was established by the AIFA in 2001. The RNF ensures the collection, management, and analysis of ICSRs across the entire Italian territory. Pharmacovigilance -responsible persons from local health units, hospital enterprises, and the National Institutes for Research and Treatment across the Italian regions and autonomous provinces have the credentials to access the RNF and upload the ICSRs made by healthcare professionals or patients/citizens, which are collected from spontaneous reports or reports from observational studies, or from those reporting ADRs that occurred during a compassionate use of drugs. Each Italian region has a regional centre of pharmacovigilance which is responsible for the quality control of ICSRs uploaded at a regional level for causality assessment, the continuous medical education in pharmacovigilance, and, together with the Italian Medicine Agency, for data-mining and signal detection activities.

We retrieved all the ICSRs that reported a drug belonging to the ATC N01A (general anaesthetic) or N01B (local anaesthetic) as suspected from the RNF for one Italian region (Campania region, Southern Italy-Supplementary Table S1), from 1 January 2001 to 7 September 2021. C.S. and G.d.M carried out the database interrogation by specifying the suspected drugs (by ATC code), the Italian region, and the time frame. ICSRs from the literature were excluded.

\subsection{Data Analysis}

Information on gender, median age, seriousness and outcome of ADR, suspected anaesthetic drug, type of reporter, and ADR distribution by System Organ Class (SOC) and Preferred Term (PT) was provided for all ICSRs. According to the document "ICH Topic E 2 D Post Approval Safety Data Management" [44], ADRs were categorised as serious when they resulted in death, or were life-threatening, required inpatient hospitalisation or prolongation of existing hospitalisation, resulted in persistent or significant disability or incapacity, or resulted in a congenital anomalies/birth defects or clinically relevant conditions based on clinical judgments. Otherwise, they were classified as not serious. Lastly, according to the national pharmacovigilance rules, the ADRs' outcome was categorised into three main categories: favourable, when the ADR recovered or improved; unfavourable, when the ADR was resolved with sequelae, remained unchanged, or induced the patient's death; and not available.

\subsection{Compliance with Ethical Standards}

Safety data derived from the Italian spontaneous reporting system are anonymous and in compliance with the ethical standard. Therefore, no further ethical measures were required.

\section{Conclusions}

We descriptively analysed ICSRs related to general and local anaesthetics that were sent to the RNF from 2001 to 2021. Our results demonstrated that a limited number of ICSRs $(n=110)$ were reported during 20 years of spontaneous reporting activities in the Campania region. Reported ADRs mainly concerned patients with a median age of 48 years and a slightly higher percentage of men. ADRs were more commonly classified as not serious and their outcome was favourable in $71 \%$ of cases. Lastly, similar characteristics were found regarding to the distribution of ADRs by SOC and PT. Indeed, both general and local anaesthetics were associated with general and cutaneous disorders, with common ADRs that included a lack of efficacy, rash, and erythema. In addition, while general anaesthetics were associated with the occurrence of respiratory disorders (bronchospasms), local anaesthetics were associated with the occurrence of nervous disorders (paralysis).

Despite the encouraging data from the Italian spontaneous reporting system on anaesthetics, we should always keep in mind that ADRs still represent a common cause of illness and even death. Thus, the continuous monitoring of these drugs, together with the obligation to declare incidents and accidents occurring in operating rooms, is highly 
recommended, especially in operating rooms and medical clinics where the medical and paramedical staff should pay attention to the occurrence of any potential anaestheticinduced ADR. In addition, the monitoring of the safety profile of these drugs is highly recommended, especially among frail populations, such as in paediatric populations for which drugs used to provide general anaesthesia have only been historically studied in adults. Thus, for this population safety and efficacy data mainly derive from real-life experience. In this context, pharmacovigilance activities have to be considered as a key component of an effective drug regulation system, clinical practice, and public health program in order to reduce harm to patients, improve public health, and reduce healthcare costs. Since underreporting still represents one of the major obstacles to the spontaneous reporting of ADRs, pharmacovigilance activities should be promoted via educational campaigns addressed to both healthcare professionals and patients. This will contribute to the encouragement of the rational and safe use of medicines.

Supplementary Materials: The following are available online at https:/ /www.mdpi.com/article/ 10.3390/ph14121261/s1, Table S1: Italian macro-regions, regions and number of inhabitants, including the study's site (Campania Region in bold).

Author Contributions: F.G., C.S., G.F.N. and A.C.; writing—original draft; F.G., C.S., G.d.M., A.D.C., A.Z., F.R., G.F.N. and A.C.; Conceptualisation, data curation, methodology, project administration, resources, investigation, and writing - review and editing. All authors have read and agreed to the published version of the manuscript.

Funding: The authors received no financial support for the research, authorship, and/or publication of this article.

Institutional Review Board Statement: Not applicable.

Informed Consent Statement: Not applicable.

Data Availability Statement: The data presented in this study are available on request from the corresponding author. The data are not publicly available due to privacy and ethical reasons as established by the Italian Medicine Agency.

Conflicts of Interest: The authors declare no conflict of interest.

\section{References}

1. Raffa, R.B.; Pergolizzi, J.V., Jr.; Taylor, R., Jr. Designing General Anesthetics That Have a Better Safety Profile. Pharmacol. Pharm. 2019, 10, 407-415. [CrossRef]

2. Skibiski, J.; Abdijadid, S. Barbiturates. In StatPearls; StatPearls Publishing: Treasure Island, FL, USA, 2021. Available online: https: / / www.ncbi.nlm.nih.gov/books /NBK539731/ (accessed on 1 November 2021).

3. López-Muñoz, F.; Ucha-Udabe, R.; Alamo, C. The history of barbiturates a century after their clinical introduction. Neuropsychiatr. Dis. Treat. 2005, 1, 329-343.

4. $\quad$ Reves, J.G.; Fragen, R.J.; Vinik, H.R.; Greenblatt, D.J. Midazolam: Pharmacology and uses. Anesthesiology 1985, 62, 310-324. [CrossRef]

5. Vinik, R.H. Co-induction: A practical application of anesthetic drug interaction. Curr. Opin. Anesthesiol. 1993, 6, S9-S13.

6. Rosenberg, M.; Weaver, J. General anesthesia. Anesth. Prog. 1991, 38, 172-186.

7. Diao, S.; Ni, J.; Shi, X.; Liu, P.; Xia, W. Mechanisms of action of general anesthetics. Front. Biosci. 2014, 19, 747-757. [CrossRef] [PubMed]

8. Alwardt, C.M.; Redford, D.; Larson, D.F. General anesthesia in cardiac surgery: A review of drugs and practices. J. Extra. Corpor. Technol. 2005, 37, 227-235. [PubMed]

9. Garmon, E.H.; Huecker, M.R. Topical, Local, and Regional Anesthesia and Anesthetics. In StatPearls; StatPearls Publishing: Treasure Island, FL, USA, 2021. Available online: https://www.ncbi.nlm.nih.gov/books/NBK430894/ (accessed on 1 November 2021).

10. Cherobin, A.C.F.P.; Tavares, G.T. Safety of local anesthetics. An. Bras. Dermatol. 2020, 95, 82-90. [CrossRef]

11. Smith, G.; D'Cruz, J.R.; Rondeau, B.; Goldman, J. General Anesthesia for Surgeons. In StatPearls; StatPearls Publishing: Treasure Island, FL, USA, 2021. Available online: https:/ / www.ncbi.nlm.nih.gov/books/NBK493199/ (accessed on 1 November 2021).

12. Stachnik, J. Inhaled anesthetic agents. Am. J. Health Syst. Pharm. 2006, 63, 623-634. [CrossRef] [PubMed]

13. Lingamchetty, T.N.; Hosseini, S.A.; Saadabadi, A. Midazolam. In StatPearls; StatPearls Publishing: Treasure Island, FL, USA, 2021. Available online: https:/ / www.ncbi.nlm.nih.gov/books/NBK537321/ (accessed on 1 November 2021). 
14. Whalley, D.G.; Maurer, W.G.; Knapik, A.L.; Estafanous, F.G. Comparison of neuromuscular effects, efficacy and safety of rocuronium and atracurium in ambulatory anaesthesia. Can J. Anaesth. 1998, 45, 954-959. [CrossRef] [PubMed]

15. Sparr, H.J.; Beaufort, T.M.; Fuchs-Buder, T. Newer Neuromuscular Blocking Agents. Drugs 2001, 61, 919-942. [CrossRef]

16. Park, K.K.; Sharon, V.R. A review of local anesthetics: Minimizing risk and side effects in cutaneous surgery. Derm. Surg. 2017, 43, 173-187. [CrossRef] [PubMed]

17. Vasques, F.; Behr, A.U.; Weinberg, G.; Ori, C.; Di Gregorio, G. A review of local anesthetic systemic toxicity cases since publication of the American Society of Regional Anesthesia Recommendations. Reg. Anesth. Pain. Med. 2015, 40, 698-705. [CrossRef]

18. Purdon, P.L.; Pavone, K.J.; Akeju, O.; Smith, A.C.; Sampson, A.L.; Lee, J.; Zhou, D.W.; Solt, K.; Brown, E.N. The Ageing Brain: Age-dependent changes in the electroencephalogram during propofol and sevoflurane general anaesthesia. Br. J. Anaesth. 2015, 115 (Suppl. S1), i46-i57. [CrossRef] [PubMed]

19. Turrentine, F.E.; Wang, H.; Simpson, V.B.; Jones, R.S. Surgical risk factors, morbidity, and mortality in elderly patients. J. Am. Coll. Surg. 2006, 203, 865. [CrossRef]

20. Martin, G.; Glass, P.S.; Breslin, D.S.; MacLeod, D.B.; Sanderson, I.C.; Lubarsky, D.A.; Reves, J.G.; Gan, T.J. A study of anesthetic drug utilization in different age groups. J. Clin. Anesth. 2003, 15, 194-200. [CrossRef]

21. Kanonidou, Z.; Karystianou, G. Anesthesia for the elderly. Hippokratia 2007, 11, 175-177. [PubMed]

22. Rademaker, M. Do women have more adverse drug reactions? Am. J. Clin. Dermatol. 2001, 2, 349-351. [CrossRef] [PubMed]

23. Zopf, Y.; Rabe, C.; Neubert, A.; Gassmann, K.G.; Rascher, W.; Hahn, E.G.; Brune, K.; Dormann, H. Women encounter ADRs more often than do men. Eur. J. Clin. Pharmacol. 2008, 64, 999-1004. [CrossRef]

24. Scavone, C.; Di Mauro, C.; Brusco, S.; Bertini, M.; di Mauro, G.; Rafaniello, C.; Sportiello, L.; Rossi, F.; Capuano, A. Surveillance of adverse events following immunization related to human papillomavirus vaccines: 12 years of vaccinovigilance in Southern Italy. Expert Opin. Drug Saf. 2019, 18, 427-433. [CrossRef]

25. Scavone, C.; Rafaniello, C.; Brusco, S.; Bertini, M.; Menditto, E.; Orlando, V.; Trama, U.; Sportiello, L.; Rossi, F.; Capuano, A. Did the New Italian Law on Mandatory Vaccines Affect Adverse Event Following Immunization's Reporting? A Pharmacovigilance Study in Southern Italy. Front. Pharmacol. 2018, 9, 1003. [CrossRef]

26. Ruggiero, R.; Fraenza, F.; Scavone, C.; di Mauro, G.; Piscitelli, R.; Mascolo, A.; Ferrajolo, C.; Rafaniello, C.; Sportiello, L.; Rossi, F.; et al. Immune Checkpoint Inhibitors and Immune-RelatedAdverseDrugReactions: Data from ItalianPharmacovigilance Database. Front. Pharmacol. 2020, 11, 830. [CrossRef]

27. Nicolson, T.J.; Mellor, H.R.; Roberts, R.R. Gender differences in drug toxicity. Trends Pharmacol. Sci. 2010, 31, 108-114. [CrossRef]

28. Becker, D.E. Adverse drug reactions in dental practice. Anesth. Prog. 2014, 61, 26-34. [CrossRef]

29. Volcheck, G.W.; Mertes, P.M. Local and general anesthetics immediate hypersensitivity reactions. Immunol. Allergy Clin. N. Am. 2014, 34, 525-546. [CrossRef]

30. Mertes, P.M.; Tajima, K.; Regnier-Kimmoun, M.A.; Lambert, M.; Iohom, G.; Guéant-Rodriguez, R.M.; Malinovsky, J.M. Perioperative anaphylaxis. Med. Clin. N. Am. 2010, 94, 761-789. [CrossRef]

31. Mitsuhata, H.; Matsumoto, S.; Hasegawa, J. The epidemiology and clinical features of anaphylactic and anaphylactoid reactions in the perioperative period in Japan. Masui 1992, 41, 1664-1669. [PubMed]

32. Light, K.P.; Lovell, A.T.; Butt, H.; Fauvel, N.J.; Holdcroft, A. Adverse effects of neuromuscular blocking agents based on yellow card reporting in the U.K.: Are there differences between males and females? Pharmacoepidemiol. Drug Saf. 2006, 15, 151-160. [CrossRef] [PubMed]

33. Gibbs, N.M.; Sadleir, P.H.; Clarke, R.C.; Platt, P.R. Survival from perioperative anaphylaxis in Western Australia 2000-2009. Br. J. Anaesth. 2013, 111, 589-593. [CrossRef]

34. Güner, M.D.; Ekmekci, P.E. Healthcare professionals' pharmacovigilance knowledge and adverse drug reaction reporting behavior and factors determining the reporting rates. J. Drug Assess. 2019, 8, 13-20. [CrossRef] [PubMed]

35. Di Mauro, G.; Zinzi, A.; Scavone, C.; Mascolo, A.; Gaio, M.; Sportiello, L.; Ferrajolo, C.; Rafaniello, C.; Rossi, F.; Capuano, A. PCSK9 Inhibitors and Neurocognitive Adverse Drug Reactions: Analysis of Individual Case Safety Reports from the Eudravigilance Database. Drug Saf. 2021, 44, 337-349. [CrossRef]

36. European Medicines Agency. Guideline on Good Pharmacovigilance Practices (GVP). 2012. Available online: https: //www.ema.europa.eu/en/documents/scientific-guideline/draft-guideline-good-pharmacovigilance-practices-module-vimanagement-reporting-adverse-reactions_en.pdf (accessed on 12 September 2021).

37. Russo, E.; Mazzitello, C.; Esposito, S.; De Francesco, A.; Capuano, A.; De Sarro, G. Pharmacovigilance in Italy: An overview. J. Pharm. Pharmacother. 2013, 4 (Suppl. S1), S20-S28. [CrossRef]

38. Naguib, M.; Magboul, M.; Jaroudi, R. Adverse Effects of General Anaesthetics: Incidence and Therapeutic Implications. CNS Drugs 1998, 10, 119-144. [CrossRef]

39. Gottschalk, A.; Van Aken, H.; Zenz, M.; Standl, T. Is anesthesia dangerous? Dtsch. Arztebl. Int. 2011, 108, 469-474. [CrossRef] [PubMed]

40. Bergman, I.J.; Kluger, M.T.; Short, T.G. Awareness during general anaesthesia: A review of 81 cases from the Anaesthetic Incident Monitoring Study. Anaesthesia 2002, 57, 549-556. [CrossRef] [PubMed]

41. Fuzier, R.; Lapeyre-Mestre, M.; Samii, K.; Montastruc, J.L.; French Association of Regional Pharmacovigilance Centres. Adverse drug reactions to local anaesthetics: A review of the French pharmacovigilance database. Drug Saf. 2009, 32, 345-356. [CrossRef] 
42. Orser, B.A.; Hyland, S.U.D.; Sheppard, I.; Wilson, C.R. Review article: Improving drug safety for patients undergoing anesthesia and surgery. Can. J. Anesth. 2013, 60, 127-135. [CrossRef]

43. Raschi, E.; La Placa, M.; Poluzzi, E.; De Ponti, F. The value of case reports and spontaneous reporting systems for pharmacovigilance and clinical practice. Br. J. Dermatol. 2021, 184, 581-583. [CrossRef] [PubMed]

44. ICH E2D Post-Approval Safety Data Management/European Medicines Agency. Available online: https://www.ema. europa.eu/en/documents/scientific-guideline/international-conference-harmonisation-technical-requirements-registrationpharmaceuticals-human-use_en-12.pdf (accessed on 16 September 2021). 